\title{
O campo da Lingüística Documentária
}

\author{
The field of Documentarian Linguistics
}

Maria de Fátima Gonçalves Moreira TÁLAMO'

Marilda Lopes Ginez de LARA²

RESUMO

Proposição do campo da Lingüística Documentária ${ }^{3}$ cuja função primordial é a de estabelecer parâmetros e modelos de elaboração de códigos para o processamento da informação - construção e recuperação - com o objetivo de responder à questão, nuclear da área de Ciência da Informação, relacionada à transformação de conteúdos registrados em elementos estruturados. Para isso, enfatizam-se, tanto os traços que relacionam este campo à revolução lingüística em curso desde o século 20, como as interfaces que tal campo mantém com as disciplinas que abordam a linguagem sob os aspectos sintático, semântico, conceitual e comunicacional, definindo-se seus problemas específicos bem como discutindo seus vértices conceituais.

Palavras-chave: Lingüística Documentária; Ciência da Informação; Linguagem Documentária.

\section{A BSTRACT}

Proposal of the field of the Documentary Linguistics whose primordial function is to establish parameters and models for the elaboration of codes in the processing of the information - its construction and retrieval. Its objective is to answer the nuclear question in the area of the Information Science, related to the transformation of registered contents into structured elements. To do so, we emphasize the aspects that relate this field to the linguistic revolution in course since the 20th. century, as well as, the interfaces that this field keeps with several disciplines that approach language through any of its aspects: syntactic, semantic, conceptual and communicational. Finally, this proposal defines the field's specific problems, arguing as well its conceptual vertices.

Key words: Documentarian Linguistics; Information Science; Documentarian Language.

\section{N TROD U Ç Ã O}

"Tinha aprendido sem esforço o inglês, o francês, o português, o latim. Suspeito, entretanto, que não era muito capaz de pensar. Pensar é esquecer diferenças, é generalizar, abstrair. No abarrotado mundo de Funes não havia senão pormenores, quase imediatos" (Funes, o memorioso, Jorge Luis Borges).

Historicamente, a atividade documentária desenvolveu-se de forma empírica como uma resposta

\footnotetext{
1 Professora Doutora, Programa de Pós-graduação em Ciência da Informação, Centro de Ciências Sociais Aplicadas, Pontifícia Universidade Católica de Campinas. Rua Marechal Deodoro, 1099, Centro, 13020-904, Campinas, SP, Brasil. Correspondência para/Correspondence to: M.F.G.M. TÁLAMO. E-mail: <mfgmtala@usp.br>.

2 Professora Doutora, Departamento de Biblioteconomia e Documentação, Escola de Comunicações e Artes, Universidade de São Paulo. São Paulo, SP, Brasil.

3 Termo originalmente sugerido por García Gutiérrez (1990).

Recebido e aceito para publicação em 26/9/2006.
} 
imediata a uma necessidade prática de sumarizar os conteúdos dos documentos. Assim, os diferentes instrumentos de tratamento da informação caracterizam-se genericamente por substituir, padronizando, uma substância ou conteúdo por uma etiqueta, limitando a avaliação objetiva tanto do processo de produção da informação, especialmente do instrumento ou meio de conversão ou tradução, quanto do resultado almejado, qual seja a capacidade de resposta consistente às questões enunciadas pelos demandantes de informação. O reconhecimento explícito que o tratamento e a disseminação da informação não consistem na formulação de verbalizações, mas na elaboração de seqüências organizadas em linguagem construída exige de forma crescente a composição de um sub-domínio na Ciência da Informação para agregar os problemas decorrentes dos processos simbólicos do tratamento e da recuperação da informação, pesquisá-los e buscar soluções que minimizem a distância entre os estoques e o uso informação. Propõe-se que esse domínio, denominado Lingüística Documentária, encarregue-se dos estudos das estruturas simbólicas da documentação e das questões lingüísticas advindas da mediação necessária entre os produtores e os consumidores de informação. Com isso, espera-se, desvincular os processos documentários da idéia que a eles se associa de verbalização autônoma e ao mesmo tempo estabelecer as fronteiras do campo da Lingüística Documentária. A hipótese de trabalho é de que o enfoque privilegiado tanto para a elaboração de linguagens documentárias quanto para a operação com as mesmas deve fundar-se na estrutura lingüística organizacional que procede de maneira metódica simultaneamente dos quadros de produção, qualquer que seja o produto simbólico resultante - índices, sites, etc. -, e do sistema cognitivocomunicatico do usuário, o qual passa então a ser submetido a uma segmentação que não a usual, tradicionalmente associada seja à natureza dos equipamentos, seja aquela dos registros. $O$ texto encontra-se distribuído em 4 partes além da Introdução. Na primeira discute-se o contexto - a revolução lingüística - que propicia o surgimento do campo ou do sub-domínio, na segunda elencam-se os seus principais problemas, na terceira apresentamse os fundamentos disciplinares de sua composição e na quarta, finalizando o texto, expõe-se algumas questões subordinadas à variação conceitual dos termos representação e informação, considerados vértices do campo proposto.

\section{Revolução lingüística: o fundamento da Lingüística Documentária}

A partir de conclusões de projetos desenvolvidos ${ }^{4}$, com o auxílio do Conselho Nacional de Desenvolvimento Científico Tecnológico (CNPq), que versam sobre a elaboração teórica das estruturas lingüísticas da documentação, pôde-se identificar a necessidade de proposição de disciplina específica, a Lingüística Documentária, compreendida como um sub-domínio da Ciência da Informação $(\mathrm{Cl})$, onde são estudadas as características da linguagem dos ambientes informacionais que combinam as referências da produção informacional, os objetivos institucionais e os elementos cognitivos e comunicacionais de grupos de usuários. Justifica-se ainda tal proposta face à necessidade crescente de formalização de conceitos do ambiente de produção, recuperação e uso da informação capazes de responder ao contínuo desenvolvimento a que se submete.

Com o advento da chamada sociedade da informação, um novo contexto de troca e de relações simbólicas vem se impondo, embora tenha sua análise muitas vezes escamoteada pela insistente afirmação da superioridade da tecnologia. Acredita-se de fato que está em jogo não apenas a afirmação de um paradigma tecnológico mas de um modelo complexo que combina três vértices: a tecnologia, o meio social e a capacidade de processamento humano do conhecimento e da informação. Ao comparar essa sociedade informacional com a sociedade de massa observase que, entre as alterações importantes que lançam, a da recepção figura como noção distintiva. Como evidenciado pelo qualificador "de massa", essa sociedade se constitui via comunicação, operando

\footnotetext{
4 Projeto: Lingüística Documentária: princípios teóricos e metodológicos, Profa. Dra. Maria de Fátima G. M. Tálamo (CNPq, 19971999). Projeto: Conceitos lingüísticos fundamentais para a organização e disseminação de informações, Profa. Dra. Marilda L. G. Lara (CNPq 2001-2004); Contribuições dos estudos sobre a linguagem e a terminologia à organização e transferência da informação (2004-2007).
} 
com produtos homogeneizantes, para um público não segmentado, cuja capacidade de seleção se encontra altamente comprometida. Já na sociedade da informação, supõe-se que para assimilar a informação e subjetivá-la, é necessário que o receptor tenha papel ativo na constituição do sentido da mensagem. A alteração do lugar da recepção acaba por determinar que o princípio da mensagem como discurso supõe a interação como a relação que sustenta a produção de sentido. Não está mais em jogo a formação de opinião mas a subjetivação da informação organizada em fluxos sociais.

A linguagem como elemento constitutivo da cultura informacional não exerce função meramente instrumental. Para além do seu funcionamento codificador, ela se propõe como representação, seja como insumo do processo social de geração de sentido, seja como resultado textual desse processo. É apenas nessa perspectiva que se pode entender a linguagem como sistema de tratamento da informação que visa, através, de sínteses, reunir, para sua recuperação, a imensa massa documental existente.

Nesse contexto, a Lingüística Documentária impõe-se como campo de estudos dos meios de representação da informação, em cujo vértice encontram-se as linguagens de processamento e produção da informação fundadas em hipóteses sobre o modo de organização de objetos integrados a conjuntos para fins de circulação do conteúdo informacional. Constitui-se, portanto, semelhante campo na interface Documentação e Lingüística Aplicada, já que, como foi dito, ele visa fundamentalmente operar com estruturas de informação inscritas em textos que permitem a sua circulação, recuperação e uso pelos públicos inseridos na cultura informacional contemporânea.

De fato, Hjelmslev (1971, p.97) já defendia a necessidade de uma lingüística prática ou aplicada levada a cabo por Saussure no início do século 20. Argumentava para tanto sobre o papel desempenhado pela linguagem na sociedade, cuja complexidade crescente, abria igualmente possibilidades de comunicação e de raciocínios jamais imaginados, com a conseqüente imposição de diversos modelos de organização simbólica. Essas novas possibilidades, nomeadas por ele de "revolução lingüística" seriam, de fato, as respostas internas do sistema simbólico ao mundo que sucede em transformações e rupturas contínuas. A reprodução mecânica da fala, permitindo a comunicação imediata a distância - como se dá no rádio - é um dos exemplos à época significativo. $O$ mesmo, mais tarde, se daria na exploração da linguagem pela propaganda. E mais a frente, cunha-se a expressão "linguagem dos meios" que ratifica por si só a previsão hjmesleviana. Assim, à epoca abria-se o leque das linguagens de comunicação associadas a funções que vão desde o entretenimento até a venda de produtos, idéias e conceitos.

A proposta de Hjelmslev encontra também abrigo na defesa que faz da forma do conteúdo como fator social. É bastante explorado o fato de que o sistema sígnico imprime forma específica simultaneamente à expressão e ao conteúdo. No entanto, como a massa total de significação que pode ser expressa através dos signos é especificamente e arbitrariamente decupada por cada sistema (grifo nosso), não só cada comunidade lingüística instituída a manipula a seu modo, como também novos sistemas nela propõem formas semânticas distintas, segundo contextos igualmente distintos. O que diferencia as línguas, nesse sentido, não é a significação que expressam mas as segmentações que as formas introduzem nas substâncias fônica e semântica. A segmentação contínua das formas de conteúdo e de expressão evidenciam que a linguagem não é substância, não expressa uma realidade semântica objetiva e homogênea.

Se é fato que a Glossemática, ao atribuir um papel central à forma, relega a um segundo plano a função, sobretudo o papel da língua na comunicação, não é menos verdade que ela abre a possibilidade de estudos lingüísticos aplicados associados ao estudo semântico das formas de conteúdo. Com isto deixa-se de observar a língua como pura expressão, o que não raro conduz o seu entendimento como verbalização, cujo exemplo é dado pela qualificação técnica dos processos documentários de tratamento da informação.

Além disso, ao comparar línguas diferentes, Hjelmslev (1971) conclui que os estudos sobre as diferentes distinções que cada uma faz no interior da substância do conteúdo tem importância direta nos destinos da humanidade, não se constituindo apenas interesse teórico, como quer estudiosos que vêm na língua uma ferramenta neutra. Isto porque a linguagem associa-se à cultura, podendo ser observada 
como resultado do trabalho seja coletivo ou não (a manipulação das formas de conteúdo expande-se em determinados períodos históricos associada a diferentes ideologias) sobre as substâncias da expressão e do conteúdo que nos leva a tê-la como um modo de vida social, reconhecendo-se nela os três fatores fundamentais no universo da cultura: o sujeito lingüístico, o sistema de signos e o contexto.

É justamente essa forma de ação que está afirmada na noção hjelmesleviana de revolução lingüística. A sociedade segundo seus modos de desenvolvimento institui novos domínios de significação, que exigem, por sua vez, a formulação de funções semióticas específicas. A sociedade contemporânea, denominada sociedade da informação, caracteriza-se pelo fato de a informação apresentar-se como insumo da ação de estar no mundo. De fato, a compreensão de que a produção de sentido nesse contexto, com todas as conseqüências que dela decorrem, introduz como requisito para emergência e consolidação da cultura informacional a construção de linguagens que visam responder de forma direta à demanda de insumos significativos para a produção de linguagem e de conhecimento.

A revolução lingüística instituída pela cultura informacional contemporânea supõe necessariamente a distinção entre sociedade de massa e sociedade da informação. E ao fazê-la reconhece que a linguagem que subsuma tal sociedade apresenta dinâmica específica que integra estruturas simbólicas, acessebilidade e contextos de uso. A Lingüística Documentária insere-se no processo de revolução lingüística, iniciado pelas linguagens de comunicação, definindose como campo de estudos das linguagens de organização de informação, sua construção para a viabilização de fluxos sociais.

Assim, cabe à Lingüística Documentária compor os quadros de referência para a análise, avaliação e construção da linguagem documentária, entendida como linguagem de informação, associando os níveis sintático-semântico-pragmático para identificar com clareza a inserção do signo documentário no plano sistêmico e no plano funcional, objetivando-o no tempo, no espaço e na cultura.

Ressalta-se ainda que a abordagem lingüística dos problemas informacionais caracteriza e conforma o núcleo da própria Ciência da Informação porque considera o universo operacional da informação relacionado diretamente à idéia da representação mediadora - a própria informação - da produção e circulação e uso do conhecimento.

\section{Os problemas da Lingüística Documentária}

Uma vez que a atividade documentária opera na linguagem e com a linguagem, é a partir da forma dessas operações e de suas características que se pode delimitar o campo da Lingüística Documentária. Conforme sugere Popper (1972, citado por SARACEVIC, 1995) não somos estudiosos de um assunto, mas dos problemas desses mesmos assuntos. No caso da Lingüística Documentária, identificam-se as questões que lhe são próprias face às especificidades da linguagem dos fluxos informacionais gerados pelas atividades da $\mathrm{Cl}$ e dos métodos para resolvê-los. Do exame das atividades documentárias é possível delimitar os problemas que a ela compete discutir e solucionar. Da atitude reflexiva sobre esses problemas nasce o campo teórico e metodológico onde são feitas as abstrações generalizantes que permitem compreender seu funcionamento das formas institucionalizadas de geração e comunicação de informações.

Uma das questões do campo remete ao conceito de informação. Face aos seus sentidos comuns, os traços nele inscritos a definem como: a) algo intencionalmente construído a partir da análise da produção do conhecimento e dos objetivos institucionais de sua disseminação, b) algo que se apresenta sob formas específicas, c) algo instaura uma relação comunicativa particular. Decorre dessa compreensão que a informação não é um dado, mas uma construção, e que sua transmissibilidade está condicionada às condições de aderência definidas por elos de significação. Essa definição tem conseqüências importantes relacionadas à necessidade de enfrentar efetivamente os problemas relacionados aos parâmetros para a construção de códigos documentários e informacionais - entre eles, a Linguagem Documentária -, e ao estabelecimento de vínculos de adesão simultaneamente com os conteúdos processados, com a instituição que os processam e com a comunidade de receptores.

Face à isso, cabe à Lingüística Documentária desenvolver e propor parâmetros para a construção 
da informação, os quais, sumariamente, relacionam-se à abordagem da produção técnico-científica e sócio-cultural, à sua representação e às formas que garantem a função sócio-cognitiva dos produtos documentários.

A elaboração dos produtos documentários desenvolve-se no interior da linguagem, caracterizando-se como um processo sucessivo de escolhas. Desde a seleção do que compõe ou não o conjunto a ser analisado, a pertinentização e a construção de conteúdos, até a definição das formas de sua disseminação está em jogo um universo de opções. A característica 'industrial' das operações documentárias (GARDIN, 1973) impede usualmente a verificação detalhada das condições de produção de cada unidade tratada, o que não subtrai da atividade a atribuição de valores no processamento do conteúdo. A abordagem da produção não autoriza uma interpretação global do seu significado, mas modeliza a informação segundo objetivos variados dependentes de políticas institucionais previamente estabelecidas.

Entende-se por modelização documentária o conjunto de operações que envolvem, depois da primeira e fundamental modelização promovida pela língua natural, aquelas próprias das atividades que dão forma aos construtos documentários e que lhes confere marcas das referências utilizadas para organizar o conjunto de informações. Para que a operação não seja aleatória, a Lingüística Documentária propõe que se constituam hipóteses de organização cujos referenciais institucionais (instituições e seus usuários) articulem quadros nocionais e linguagem compartilhadas no interior de domínios do saber ou de atividades. A formalização dessas hipóteses em linguagem combina dados da produção e da recepção, garantindo-se assim o caráter socializado da informação documentária.

Partindo do princípio que a interação comunicativa transcende a produção de efeitos, qual um esquema unidirecional emissor-receptor, a construção de produtos documentários deve também observar as particularidades das trocas simbólicas próprias da linguagem. Supõe-se que a transferência da informação via mensagens documentárias é uma operação de mão dupla, uma troca qualificada em que estão em jogo ações interativas. Por razões que combinam os propósitos de disponibilização e permanência (TÁLAMO, 1994) e em função do tamanho do universo sempre crescente da produção, os produtos documentários (representação documentária, informação documentária) são formulações sintéticas, condensadas. Sob essa perspectiva, a mensagem documentária é indireta, e o construto formulado em linguagem - a própria informação documentária - objetiva desencadear um processo semiótico particular que vai dos indicadores (os produtos documentários propriamente ditos) para a informação e desta para a produção.

Essa característica confere aos produtos documentários uma feição generalizante, e seu poder de representação não deve ser interpretado como identidade, já que as idéias são contemporâneas das palavras que as exprimem. A língua só funciona como sistema de comunicação quando funciona ao mesmo tempo como instrumento de construção do saber a ser comunicado (LOPES, 1997).

Ocorre, porém, que o isolamento das 'representações' relativamente aos seus textos de origem provoca a perda de interpretantes contextuais. A interpretação não arbitrária do significado dessas representações exige sua recontextualização, passível de ser obtida através de terminologias específicas. Disso decorre que a Lingüística Documentária não apresenta um componente semântico autônomo, mas de relações de sentido inscritas nos universos temáticos inscritos nas terminologias.

\section{Fundamentos da Lingüística Documentária}

Como já afirmado, a motivação da Lingüística Documentária relaciona-se ao atendimento às necessidades informacionais provenientes, hoje, da crescente complexidade a que se submete a sociedade. Tomando a atividade documentária como gênero de prática social, os produtos documentários apresentam a informação como resultado de organização, mediando a produção e a demanda. Para dar conta dos problemas que tal atividade propõe, a Lingüística Documentária se desenvolve principalmente a partir da apropriação dos conceitos da Lingüística Estrutural, da Semiótica, da Terminologia e da Lógica Formal. Essa apropriação se faz de modo coordenado, não se propondo apenas como uma junção, o que permite definir o campo através da interdisciplinaridade que Ihe é inerente. 


\section{A Lingüística}

A referência que aqui se faz ao sistema lingüístico visa a identificar os aspectos relacionados à sua estruturação relacional, à sua natureza arbitrária e à sua autonomia. A partir deles, entende-se a Linguagem Documentária como estrutura que opera os conteúdos documentados, articulando-os em esquemas classificatórios. A língua é também vista na perspectiva de suas funções no processo lingüístico. Portanto, sob o epistema estruturalista - compreendido como metaconceito metodológico -, observam-se as propriedades estruturais da língua e, sob o parâmetro comunicacional (considerando os desenvolvimentos da Lingüística Estrutural), suas funções nos atos de comunicação verbal. Dessas abordagens deriva um modelo de linguagem documentária como linguagem construída e intermediária, definida quer pelo seu papel - ponte para a comunicação sistema-usuário - quer pelas suas semelhanças e diferenças relativamente à linguagem natural e à linguagem artificial. As analogias entre ambas as linguagens referendam, também, a necessidade da formalização dos arranjos dos elementos que compõem a linguagem documentária como condição para um sistema autônomo, uno e dotado de significado próprio.

Para fins de elaboração de linguagens documentárias interessa, portanto, o domínio das estruturas do sistema lingüístico. Um dos conceitos importantes para isso é o de valor. Adiferença e a identidade são noções relacionais estabelecidas a partir de valores. O valor, por sua vez, é uma entidade opositiva a partir da qual podem ser feitas discriminações sucessivas. Quando Saussure fala que 'na língua não há senão diferenças', quer com isso dizer que o significado define-se tanto como valor negativo, paradigmático (uma palavra significa tudo o que as outras não significam), quanto como valor positivo, sintagmático (uma palavra significa a partir daquelas que a rodeiam). Se a definição negativa, paradigmática, é inalterável na língua, é alterável na fala, pelas possibilidades quase infinitas de contraste que uma palavra pode ter com outras palavras. A partir disso, evidencia-se que a linguagem é uma organização - um sistema, uma estrutura. A determinação do significado de suas unidades pressupõe seu relacionamento mútuo e sua posição na organização do conjunto.
Globalmente, essa organização representa o mundo. Diz-se representa porque está no seu lugar. O real é, nesse sentido, ilusório porque a relação entre a ordem lingüística e o mundo funda-se na analogia e semelhança, e não na identidade. Sob o ponto de vista da cultura, tal representação apresenta-se como convenção fundante que resulta das operações de recorte sobre o continuum da realidade. Os significados são, entretanto, autônomos, resolvendo-se no interior da própria linguagem à base de oposições.

Este modelo, porém, reflete as limitações de uma linguagem construída. De fato, a Linguagem Documentária tem só duas das funções características da linguagem natural (a referencial e, a seu modo, a metalingüística), apenas a primeira articulação (de onde a ausência de produtividade - não se fala uma Linguagem Documentária) e uma realização precária no eixo das combinações (o eixo sintagmático).

Posto que a ação de significar é um fato do discurso - já que o significado da língua é apenas sua matéria prima (LOPES, 1997) - não podemos falar verdadeiramente de um 'discurso documentário's, a não ser considerando essas restrições. As mensagens 'documentárias', segundo o modelo hoje vigente, também têm formato substancialmente diferente das mensagens lingüísticas. Esse fato enuncia uma questão que merece reflexão e exige novos instrumentos para potencializar, no nível sintagmático, a capacidade de tal linguagem produzir enunciados mais próximos aos da linguagem natural, o que possivelmente responderia por processos comunicacionais mais eficientes.

Observa-se que as propostas sedimentadas na Lingüística Estrutural ainda refletem os desenvolvimentos experimentados pela própria disciplina, incluindo-se aí as críticas a ela dirigidas. Dentre outras, destaca-se a excessiva centralidade na análise da langue em detrimento da parole e a exigência de uso dos princípios semióticos para a melhor compreensão do desenvolvimento do processo interpretativo.

\section{A Semiótica}

O ponto de partida da Semiótica é distinto do da Lingüística Estrutural. Na perspectiva de Peirce, o conceito fundamental a ser observado é o da a

\footnotetext{
5 Via terminologias concretas - considerando que estas são constituídas a partir dos discursos de domínios e áreas de atividade - recupera-se, indiretamente, a dinamicidade da língua realizada. Mas as terminologias também sofrem os efeitos da perda de dinamicidade.
} 
semiose, enquanto processo onde alguma coisa funciona como signo para alguém sob algum aspecto, e que compreende o signo, ou representamen, o interpretante e o objeto, ao qual se acrescentou depois o intérprete e o contexto, segundo proposta de Morris. Já para Saussure, o ponto de partida é o fato social subjacente a todo ato de fala, ou seja, a língua (DASCAL, 1978). A combinação das duas perspectivas permite considerar os aspectos pragmáticos à realização do ato sígnico (incluindo-se aí o ato da fala que Saussure havia 'deixado de fora'), que são os elementos do contexto, das circunstâncias de enunciação e do usuário.

Recorrendo-se à noção de processo sígnico (e particularmente às noções de signo, interpretante, semiose e experiência colateral) é possível compreender com maior precisão o estatuto da linguagem documentária: sua interpretação remete necessariamente ao 'vivido' nas ciências e nas técnicas (GRANGER, 1974). Observa-se, ao mesmo tempo, que, se a noção de semiose ilimitada é bastante pertinente para operar a linguagem comum, na $\mathrm{Cl}$ esse processo interpretativo necessariamente encontra seus embreantes ${ }^{6}$ nas linguagens das áreas-foco eleitas pelos sistemas de informação (lembremos que a informação é sempre institucional). Há então que se buscar referências interpretativas possíveis e controladas para que os 'signos documentários' (a linguagem documentária ou os seus elementos) não sejam interpretados exclusivamente a partir da língua geral e da experiência particular de cada indivíduo.

A Semiótica também contribui para mostrar que um sistema sígnico (a Linguagem Documentária funciona como um gênero de sistema sígnico particular) deve ser abordado como elemento de processos comunicacionais e, simultaneamente, de processos de significação. Seguindo as teorias contemporâneas, a observação do signo documentário deve integrar os aspectos semânticos, sintáticos e pragmáticos separáveis apenas por razões didáticas.

Como decorrência do que foi exposto, entende-se por signo documentário: a) um signo de um código razoavelmente impreciso e incompleto, muitas vezes circunstancial, cuja conformação remete originalmente ao signo lingüístico mas é deficiente em relação a ele na sua potencialidade de realização como unidade comunicativa e significativa. Ele pode remeter, também, a símbolos não-lingüísticos mas passíveis de tradução lingüística. O signo documentário se mostra, nesse sentido, como uma unidade de uma linguagem intermediária. Logo, o seu funcionamento depende necessariamente de outros sistemas semióticos;

b) parte de um sistema sígnico cuja unidade mínima é o descritor, isto é, um elemento indivisível, já que a sua divisão o descaracterizaria como conceito. Os descritores podem coincidir com a palavra, porém são mais freqüentemente expressos como sintagmas nominais. Nunca constituem argumentos, mas termos simples ou descrições, ou ainda proposições, caso sejam considerados a partir de definições. Considera-se, portanto, que a impossibilidade de formular argumentos (ou melhor, simulá-los por analogia ao argumento enquanto produto de um raciocínio complexo) seja a sua principal limitação.

\section{A terminologia}

A Lingüística e a Semiótica nas quais a Lingüística Documentária busca seus fundamentos não resolvem os problemas de delimitação de subconjuntos lingüísticos temáticos e funcionais. A organização de campos semânticos de Trier, a organização do universo semântico de Greimas, como o modelo de Katz e Fodor (de origem chomskyana), entre outras, não oferecem instrumental concreto à $\mathrm{Cl}$ para a elaboração de suas linguagens, porque seus pontos de partida são especulativos. A Terminologia, porém, permite dar conta desses elementos nos seus aspectos teórico-metodológicos e materiais.

No entanto, a Terminologia também é uma disciplina que conhece transformações no seu desenvolvimento, sendo distintamente concebida em razão dos diferentes pontos de partida adotados. A Teoria Geral da Terminologia (TGT) é tributária da linha

\footnotetext{
- O termo 'embreagem' é utilizado por Granger para falar dos interpretantes que definem as significações nas Ciências cujas evocações não são indefinidas, mas remessas estruturadas, ou em estruturação, no simbolismo das próprias ciências. Diferentemente da embreagem nas línguas naturais, que dependem do conhecimento lingüístico, do uso da língua e da experiência dos indivíduos (e em função da característica de dupla articulação das línguas), a interpretação nos sistemas simbólicos formais depende de seu significado (1ª articulação) tal como foi definido nas próprias ciências correspondentes, e que se ordenam apenas à experiência dos próprios símbolos (GRANGER, 1974, p.138).
} 
cognitiva: concebe a formação do conceito como algo independente da língua e vê no signo lingüístico apenas a parte significante, atribuindo-lhe uma função meramente instrumental a serviço da denominação. A Teoria Comunicativa da Terminologia, bem mais recente, faz críticas ao reducionismo da TGT (embora não negue sua coerência interna), propondo observar o fenômeno terminológico no interior da linguagem a partir de seu caráter comunicativo. Já a Socioterminologia ressalta o uso social dos termos, rejeitando a excessiva ênfase dada à normalização pela TGT.

A TGT, ao privilegiar a concepção triádica da significação à maneira de Ogden \& Richards (símbolo, significado ou conceito, referente), compartilha do realismo que atribui ao referente uma materialidade passível de ser representada fielmente pelo conceito. O signo lingüístico (o símbolo, na tríade acima) tem caráter apenas funcional, porque é determinado posteriormente à formação do conceito, para sua denominação. A TGT compartilha também do mentalismo, uma vez que reduz o significado a uma coisa mental, desligada das línguas. Embora o mentalismo não esteja ligado à tríade, ele remete a mediação ao conceito psicológico. Como decorrência, a TGT é prescritiva e normativa, não admite a variação e a sinonímia, prega a univocidade interpretativa via padronização como o único meio para a comunicação. Em última análise, a TGT pressuporia a possibilidade de uma 'linguagem perfeita e universal' (ECO, 2001).

A Teoria Comunicativa da Terminologia e a Socioterminologia, em distintas perspectivas, relativizam (ou não aceitam) a formação do conceito como algo fora das línguas. Tende-se a observar o termo como um signo lingüístico (significante/significado), portanto definível em relação a outras realidades da mesma ordem, no interior das próprias formações lingüísticas. Pode-se pressupor que estas teorias substituiriam o triângulo de Ogden \& Richards pelo peirceano, uma vez que, até para Peirce, o Objeto só interessa em relação aos índices e ícones: o símbolo é da ordem convencional (GRANGER,1974).

A Lingüística Documentária se apropria da Terminologia em vários sentidos e momentos. A Terminologia fornece referências teórico-metodológicas necessárias à compreensão e formulação das redes lógico-semânticas, observando-se uma relação estreita entre a norma documentária para elaboração de tesauros (ISO 2788) e as normas terminológicas (ISO 704 e ISO 1087). As terminologias concretas, por sua vez, fornecem o referencial interpretativo para os descritores (os termos funcionam como operadores de sentido) e para a linguagem documentária de um modo geral: oferecem procedimentos para a delimitação dos universos-foco, orientam a identificação dos domínios e dão sustentação à construção das redes relacionais, seja pela definição dos termos, seja pela identificação das características para compor as estruturas de relacionamento. Em todo caso, ao fornecer referências para a significação, as terminologias propiciam o desenvolvimento da semiose documentária.

A diferentes orientações teóricas da Terminologia implicam diferentes formas de abordagem dos universos temático-funcionais, que variam de uma orientação prescritiva, mais rígida e normalizadora, para uma descritiva, mais flexível e apta a incorporar melhor a linguagem e os referenciais dos usuários. As diferentes tendências também podem se rebater nos privilégios dos aspectos semântico, sintático e pragmático dos termos, se é possível falar deles de forma separada.

\section{CONSIDERAÇÕES FINAIS}

O corpo de conceitos da Lingüística Documentária não goza, até o momento, de estabilidade. Há ainda uma variação denominativa muito grande que expressa o estágio embrionário dos contornos desse domínio. Essa é, no entanto, apenas uma característica de estruturação do campo. Dentre os inúmeros conceitos que fazem parte do campo, os conceitos de representação e informação documentárias são nucleares, razão pela qual esboçam-se os seus contornos a seguir.

Representação é um conceito enfrentado de forma heterogênea pela lingüística, semiótica, como também sociológica e filosófica. As distintas formas de compreendê-lo têm sua origem nos diferentes modos de conceber a relação entre a representação e o objeto ou fenômeno representado. De um lado, a representação supõe uma relação mimética entre representação e objeto/fenômeno representado; de outro, é produto de mediação marcado pelas distintas práticas sociais. Às teorias ditas representacionais opõem-se, recentemente, aquelas que questionam a própria idéia de representação. As diferentes abordagens sobre representação se refletem nos discursos das áreas do conhecimento. No caso da $\mathrm{Cl}$, a crítica 
é predominantemente feita a partir da concepção de representação como espelho (CAPURRO, 2003), mas não é dessa forma que a Lingüística Documentária delimita o conceito.

Para a Lingüística Documentária a idéia de representação é operacional e antecede a delimitação do conceito de informação documentária. A idéia pressuposta no conceito de representação tem o objetivo de mostrar que ela é algo que está em lugar de alguma coisa para alguém sob um determinado aspecto. Enquanto uma concepção semiótica, supõe uma relação em que o signo, ou representamen, funciona como desencadeador de um interpretante cujas referências dependem de experiência colateral que, para a linguagem documentária, combina elementos institucionais e terminológicos, como já se observou anteriormente. Já enquanto linguagem (e por analogia às funções das línguas naturais), verifica-se que a representação, além de não ser a principal função da língua, é admitida como construção realizada no processo comunicacional (a língua, ao funcionar como instrumento de comunicação funciona, simultaneamente, como meio de construção do conteúdo 'representado').

Para auxiliar no descarte da idéia de identidade ou mimmesis, a Lingüística Documentária propõe substituir o termo representação documentária por

\section{REFERÊNCIAS}

CAPURRO, R. Foundations of information science: review and perspectives. (Enlarged version). Available from: <www. capurro.de/tampere91.htm>. Acess: 29 Sept. 2003.

DASCAL, M. Las sémiologies contemporaines. In: DASCAL, M. La sémiologie de Leibniz. Paris: Aubier Montaigne, 1978. cap.2.

ECO, U. A busca da língua perfeita. Bauru: EDUSC, 2001.

GARCÍA GUTIÉRREZ, A. Estructura linguística de la documentación: teoría y método. Murcua: Universidad de Murcia, 1990.

GARDIN, J.-C. Document analysis and linguistic theory. The Journal of Documentation, v.29, n.2, p.137-168, 1973.

GRANGER, G.G. Filosofia do estilo. São Paulo: Perspectiva, 1974. (Estudos, 29).

HJELMSLEV, L. Essais Linguistique. Paris: Editions de Minuit, 1971. p.97-99.

ISO 1087-1. Terminology - vocabulary. Genève: International Standard Organization, 2001.

ISO 704. Principles and methods of terminology. Genève: International Standard Organization, 2000. informação documentária, com a vantagem de que este termo, além de circunscrever melhor o conceito no interior de seu campo específico, constitui um amadurecimento em relação à idéia de representação de conteúdos.

Quanto ao significado veiculado pela informação documentária, o aspecto central para a Lingüística Documentária - para além da arbitrariedade da relação significante/significado -, é que a identificação do significado é negativa, oposicional, relacional. Os signos documentários significam exclusivamente de forma relacional, porém não na língua geral, mas no interior de linguagens construídas com base nos conceitos (termos) das linguagens especializadas dos domínios de saber e de atividades.

O significado da informação documentária, portanto, não é exterior à linguagem, mas dependente da noção de arranjo da própria linguagem documentária. A motivação dessa significação é explicitada pela hipótese de organização, cuja formulação é fundada na articulação da linguagem de especialidade e da linguagem dos usuários expressa por categorias de organização dos domínios, categorias textuais e ideacionais contextualizadas nos espaços de trânsito da informação definidos por políticas institucionais.
ISO-2788; BS5723. Guidelines to establishment and development of monolingual thesauri. Genève; London: International Standard Organization, 1986/1987.

LARA, M.L.G.L. Conceitos lingüísticos fundamentais para a organização e disseminação de informações. In: ENCONTRO NACIONAL DE PESQUISA EM CIÊNCIADA INFORMAÇÃO, 5., 2003, Belo Horizonte. Anais... Belo Horizonte: ENANCIB, 2003.

LARA, M.L.G.L. Contribuições dos estudos sobre a linguagem e a terminologia à organização e transferência da informação: plano de trabalho apresentado ao CNPq para obtenção de Bolsa PQ. São Paulo: ECA-USP, 2003.

LOPES, E. A identidade e a diferença. São Paulo: EDUSP, 1997.

SARACEVIC, T. Interdisciplinary nature of information science. Ciência da Informação, Brasília, v.24, n.1, p. 36-48, 1995.

TÁLAMO, M.F.G.M. Linguagem documentária. São Paulo:APB (Ensaios APB, n.45), 1994.

TÁLAMO, M.F.G.M. Lingüísstica Documentária: delimitação do campo e conceitos teóricos e metodológicos. In: ENCONTRO NACIONAL DE PESQUISA EM CIÊNCIADA INFORMAÇÃO. 3., 1997, Rio de Janeiro. Anais... Rio de Janeiro: ANCIB, 1997. p.37. 
